\title{
COLLABORATIVE GOVERNANCE DALAM PENCEGAHAN KEBAKARAN HUTAN DAN LAHAN GAMBUT
}

\author{
Tri Maylani dan Dadang Mashur \\ FISIP Universitas Riau, Kampus Bina Widya Km. 12,5 Simpang Baru Panam, Pekanbaru 28293
}

\begin{abstract}
Forest and peatland fires in Kabupaten Bengkalis are one of the environmental problems that often occur and are considered important so that it becomes the government's attention. To overcome this problem, the government involves various parties such as the private sector and the community to be able to work together in overcoming the problem of forest and peat land fires called collaborative governance. The purpose of this study is to find out collaborative governance in the prevention of forest and peat land fires in Kabupaten Bengkalis. The theory used is the theory of the process of inter-organizational collaboration by Huxham and Siv Vangen, namely there are six processes: managing aims; compromise; communication; democracy and equality; power and trust; determination, commitment and stamina. This study uses a type of qualitative research obtained through interview techniques, observation and documentation. The results of this study indicate that collaborative governance in the prevention of forest and peatland fires in Kabupaten Bengkalis has not maximal. There are several indicators that have not been maximized, there are managing aims; compromise and communication, while democracy and equality; power and trust; and determination, commitment and stamina have gone well.
\end{abstract}

\begin{abstract}
Abstrak: Kebakaran hutan dan lahan gambut di Kabupaten Bengkalis merupakan salah satu masalah lingkungan yang sering terjadi dan dianggap penting sehingga menjadi perhatian pemerintah. Untuk mengatasi masalah ini, pemerintah melibatkan berbagai pihak seperti sektor swasta dan masyarakat untuk dapat bekerja sama dalam mengatasi masalah kebakaran hutan dan lahan gambut yang disebut collaborative governance. Tujuan dari penelitian ini adalah untuk mengetahui collaborative governance dalam pencegahan kebakaran hutan dan lahan gambut di Kabupaten Bengkalis. Teori yang digunakan adalah teori proses kolaborasi antar organisasi oleh Huxham dan Siv Vangen, yaitu ada enam proses: tujuan; kompromi; komunikasi; demokrasi dan kesetaraan; kekuatan dan kepercayaan; tekad, komitmen dan stamina. Penelitian ini menggunakan jenis penelitian kualitatif yang diperoleh melalui teknik wawancara, observasi dan dokumentasi. Hasil penelitian ini menunjukkan bahwa collaborative governance dalam pencegahan kebakaran hutan dan lahan gambut di Kabupaten Bengkalis belum maksimal. Ada beberapa indikator yang belum maksimal, yaitu: tujuan, kompromi dan komunikasi, sementara demokrasi dan kesetaraan; kekuatan dan kepercayaan; dan tekad, komitmen dan stamina telah berjalan dengan baik.
\end{abstract}

Kata Kunci: collaborative governance, pencegahan kebakaran, lahan gambut

\section{PENDAHULUAN}

Kabupaten Bengkalis merupakan salah satu Kabupaten di Provinsi Riau yang memiliki potensi hutan yang besar yaitu sekitar 903, 920.0 Ha. Kabupaten Bengkalis juga memiliki potensi lahan gambut yang luas. Sebagian besar wilayah Kabupaten Bengkalis merupakan tanah organosol, yaitu jenis tanah yang banyak mengandung bahan organik tebal, seperti gambut. Luas lahan gambut diwilayah Kabupaten Bengkalis, yaitu 1.240.122 Ha Kawasan Hidrologis Gambut (KHG) dan $474.383 \mathrm{Ha} \mathrm{Ka-}$ wasan Lindung Gambut (KLG).

Keberadaan hutan dan lahan gambut di Kabupaten Bengkalis semakin hari semakin berkurang. Hal ini disebabkan oleh kebakaran hutan dan lahan yang terjadi beberapa tahun belakangan sangat luas dan sampai saat ini masih belum bisa diselesaikan secara tuntas. Berdasarkan sumber penyebabnya, kebakaran hutan dan lahan dapat dikelompokkan menjadi dua, yaitu kebakaran hutan dan lahan yang terjadi secara alami dan kebakaran hutan dan lahan yang terjadi akibat ulah manusia. Kejadian kebakaran hutan dan lahan di Kabupaten Bengkalis sebagian besar diakibatkan oleh aktivitas manusia dalam rangka pembukaan lahan, baik untuk usaha pertanian maupun perkebunan yang ditunjang oleh kondisi iklim dan adanya fenomena alam.

Kebakaran hutan dan lahan di Kabupaten Bengkalis mengalami puncaknya pada periode tahun 2015 dan 2016 dimana terjadi sebanyak 283 kasus dengan luas terbakar $1251 \mathrm{Ha}$ dan 
378 kasus dengan luas terbakar $1.345 \mathrm{Ha}$, sehingga mengalami masa yang sangat sulit dalam melaksanakan penanggulangan bencana. Hal ini disebabkan luasnya jumlah kebakaran hutan dan kebakaran terjadi pada lahan gambut yang sulit dipadamkan sehingga dampak asap yang ditimbulkan pada tahun 2015 dan 2016 merupakan bencana kabut asap yang sangat parah. Data juga menunjukkan fakta bahwa pada tahun 2018 kembali mengalami peningkatan kasus kebakaran hutan dan lahan, yaitu sebanyak 113 kasus dengan luas yang terbakar 655,615 Ha.

Kecamatan Bandar Laksamana merupakan kecamatan yang paling luas kasus kebakarannya yakni sebanyak 2 kasus dengan luas terbakar 145,7 Ha. Mayoritas lahan yang terbakar merupakan lahan milik masyarakat yang diduga dibakar pada saat melakukan pembersihan lahan (land clearing) dan didukung oleh cuaca panas. Kebakaran yang terjadi relatif sulit untuk dipadamkan. Walaupun api di permukaan sudah padam, bukan berarti api di lapisan dalam juga padam. Api tersebut bisa bertahan berbulan-bulan bahkan menjalar ke tempat lain. Api yang menjalar ke bawah permukaan tanah menyebabkan pembakaran yang tidak menyala sehingga hanya asap putih yang tampak di atas permukaan. Hal inilah yang menyebabkan kegiatan pemadaman kerap sulit dilakukan. Ditambah lagi lokasi hutan dan lahan yang terbakar jauh masuk ke dalam sehingga sumber air susah untuk didapatkan. Pemadaman api pada lahan gambut memerlukan penanganan khusus dan peralatan yang memenuhi standar sedangkan peralatan yang dimiliki oleh pemerintah kurang memadai. Penanggulangan (pemadaman) relatif tidak efektif dalam mengendalikan kebakaran hutan dan lahan, meskipun pengorbanan biaya cukup besar.

Pengendalian kebakaran hutan dan lahan membutuhkan sistematika yang tersusun rapi untuk mencapai tujuan. Pengendalian kebakaran hutan dan lahan sendiri dimulai dalam tiga tahapan yaitu pencegahan, penanggulangan (pemadaman) serta pemulihan paska kebakaran. Namun tahapan yang dilakukan oleh jajaran pemerintah hanya pada tahapan pena- nggulangan (pemadaman) kebakaran hutan dan lahan. Penguatan upaya pencegahan menjadi pilihan sangat penting dalam pengendalian kebakaran hutan dan lahan. Melalui pencegahan sejak dini, dampak-dampak yang ditimbulkan akibat kebakaran hutan dan lahan baik itu dari segi lingkungan, ekologi, ekonomi, sosial budaya, dan politik bahkan merugikan negara dapat dicegah. Pencegahan bukan hanya semata sosialisasi kepada masyarakat tentang larangan membakar. Akan tetapi pencegahan lebih ditujukan bagaimana agar api tidak dinyalakan atau api kecil dapat dipadamkan sebelum kebakaran meluas sehingga sulit untuk dikendalikan.

Lambatnya penanganan masalah kebakaran hutan dan lahan selama ini disebabkan oleh peran pemerintah maupun masyarakat belum nyata. Masih terpusat pada aspek pemadaman sedangkan pencegahan belum dioptimalkan. Peran para pihak, satuan pengendalian kebakaran, regu pemadam, dan masyarakat peduli Api (MPA) dalam upaya pencegahan dan pemadaman belum optimal. Peraturan yang berkaitan dengan kebakaran hutan dan/atau lahan, belum sepenuhnya mampu memfasilitasi dan meningkatkan koordinasi, integrase, sinkronisasi dan sinergi untuk menjamin pencegahan kebakaran di tingkat bawah (lapangan) secara baik. Meskipun peraturan dan sanksi dapat mengurangi faktor manusia sebagai penyebab kebakaran, namun tindakan hukum ini membutuhkan pengawasan yang ketat di lapangan agar dampaknya berkelanjutan.

Pemerintah sendiri menyadari kebakaran hutan dan lahan merupakan suatu bencana atau masalah bersifat multidimensi yang memerlukan kerjasama dari berbagai pihak untuk menanganinya. Dalam melaksanakan pencegahan kebakaran hutan dan lahan, pemerintah tidak bisa bekerja sendiri, peran swasta dan masyarakat sangat dibutuhkan untuk meningkatkan keberhasilan dalam pencegahan kebakaran hutan dan lahan ini.

Kerja sama antar pemangku kepentingan dalam penyelenggaraan pemerintahan dilakukan sebagai suatu usaha dan respon pemerintah dalam kegiatan penanganan masalah publik 
yaitu masalah kebakaran hutan dan lahan gambut. Istilah kerja sama antar pemangku kepentingan yang melibatkan pemerintah, swasta, dan masyarakat dapat diartikan sebagai collaborative governance. Pemerintah dalam hal ini, yaitu Badan Penanggulangan Bencana Daerah Kabupaten Bengkalis, Dinas Pemadam Kebakaran Kabupaten Bengkalis, Dinas Lingkungan Hidup Kabupaten Bengkalis dan Polres Bengkalis. Swasta yang dimaksud adalah PT Bukit Batu Hutani Alam yang notabenenya bertanggung jawab. Masyarakat yang dimaksud adalah anggota MPA yang juga berperan aktif dalam masalah penanganan kebakaran hutan dan lahan.

Peran pemerintah dalam proses collaborative governance dalam pencegahan kebakaran hutan dan lahan gambut di Kabupaten Bengkalis adalah sebagai koordinator, regulator dan fasilitator yang menyediakan regulasi, sanksi hukum, penganggaran dana, sosialisasi, pelatihan, penyediaan sarana dan prasarana dalam pencegahan kebakaran hutan dan lahan. Kemudian peran swasta dalam proses collaborative adalah sebagai fasilitator yang menyediakan sarana dan prasarana pencegahan kebakaran, membentuk regu pemadam kebakaran, pelaporan dan pengawasan di sekitar lokasi perusahaan dan setiap perusahaan mempunyai tanggung jawab terhadap pencegahan kebakaran hutan dan lahan. Sedangkan peran masyarakat dalam hal ini MPA dalam proses collaborative adalah sebagai katalisator yang melakukan pencegahan dini, pemadaman dini dan monitoring.

Bentuk kerjasama yang dilakukan pemerintah, swasta dan masyarakat dalam pencegahan kebakaran hutan dan lahan gambut adalah bekerjasama dalam sosialisasi, apel siaga darurat, patrol gabungan, penyediaan fasilitas untuk masyarakat peduli api, penyediaan data, pertukaran informasi, laporan setiap bulan, dan pembinaan MPA. Bentuk kerjasama yang dilakukan belum ada berupa suatu program kerja terstruktur yang melibatkan ketiga stakeholder tersebut secara langsung untuk meningkatkan penyelenggaraan pencegahan kebakaran hutan dan lahan gambut.

\section{METODE}

Penulis melakukan penelitian ini secara bertahap, terdiri dari: 1) Observasi (pengamatan), agar penulis mendapatkan gambaran selengkap mungkin, maka penulis mengadakan pengamatan dan mencatat secara sistematis terhadap gejala dan fenomena yang ada di lapangan yang berhubungan dengan collaborative governance dalam pencegahan kebakaran hutan dan lahan gambut di Kabupaten Bengkalis. 2) Interview (wawancara), wawancara dilakukan secara bertahap berdasarkan informan-informan yang sudah ditetapkan sekaligus melakukan survei ke lokasi penelitian untuk melihat keadaan yang nyata di lapangan. Hasil wawancara yang didapatkan oleh peneliti dari narasumber yang berbedabeda di analisis dan dipahami secara mendalam setelah itu direkap menjadi hasil analisis dan di dukung dengan hasil survey yang ditemukan di lapangan. 3) Dokumentasi, penulis mengambilan data yang bersumber dari dokumen-dokumen yang didapat dari informan yang ada hubungannya dengan collaborative governance dalam pencegahan kebakaran hutan dan lahan gambut berupa file, foto, buku profil, laporan akhir dan sebagainya.

\section{HASIL DAN PEMBAHASAN}

Collaborative governance dalam pencegahan kebakaran hutan dan lahan gambut di Kabupaten Bengkalis jika proses kolaborasinya terlaksana dengan baik, maka akan menghasilkan manfaat yang sangat besar baik untuk lingkungan, masyarakat, daerah maupun negara mengingat beberapa tahun belakangan kebakaran hutan dan lahan menjadi fenomena yang menjadi perbincangan publik dan menimbulkan banyak kerugian bagi negara.

Collaborative governance dalam pencegahan kebakaran hutan dan lahan gambut di Kabupaten Bengkalis adalah kolaborasi atau kerjasama yang dilakukan oleh pemerintah, swasta dan masyarakat dalam melakukan pencegahan agar tidak terjadinya kebakaran atau meminimalisir terjadinya kebakaran. Dalam artian collaborative governance diharapkan 
mampu menjadi sebuah solusi dalam menangani masalah kebakaran hutan dan lahan gambut yang mengandalkan proses kerjasama saling melengkapi antara pemerintah, swasta dan masyarakat.

\section{Managing Aims}

Dimensi ini memfokuskan pada sebuah pernyataan tujuan terjadinya kolaborasi. Dalam proses kolaborasi, setiap pihak yang terkait, yaitu pemerintah, swasta dan masyarakat harus memiliki tujuan yang sama atau dengan kata lain memiliki suatu tujuan yang ingin dicapai bersama. Pemerintah, swasta maupun masyarakat dalam berkolaborasi dalam pencegahan kebakaran hutan dan lahan gambut pada dasarnya mempunyai tujuan yang sama meskipun menggunakan kata-kata dan bahasa yang berbeda yaitu untuk bersama-sama mencegah agar kebakaran hutan dan lahan gambut tidak terjadi lagi karena tanggung jawab dalam mencegah terjadinya kebakaran hutan dan lahan gambut tidak hanya satu pihak saja namun memerlukan kerjasama antara pemerintah, swasta dan masyarakat.

Kolaborasi pemerintah, swasta dan masyarakat merupakan media strategis dalam mewujudkan dan mendukung tujuan tersebut. Pendekatan kolaborasi ini dimaksudkan agar dalam pencegahan kebakaran hutan dan lahan gambut bukan saja tanggung jawab pemerintah dan swasta tetapi peran serta masyarakat ikut menentukan keberhasilan dan terwujudkan tujuan tersebut. Namun kolaborasi dalam pencegahan kebakaran hutan dan lahan gambut belum tercapai sepenuhnya hal ini terjadi karena ada beberapa faktor seperti faktor alam yang membuat tujuan tersebut belum tercapai sepenuhnya walaupun pemerintah, swasta dan masyarakat sudah melakukan usaha yang maksimal agar kebakaran tidak terjadi lagi.

\section{Compromise}

Kompromi dilakukan dengan cara menciptakan jalan tengah yang mengakomodasikan pihak lain dan menghilangkan persepsi stereotype terhadap pihak lain. Masalah-masalah yang terjadi pada collaborative governance dalam pencegahan kebakaran hutan dan lahan gambut harus diselesaikan dengan cara menciptakan jalan tengah agar tidak terjadi perbedaan persepsi dalam pembagian tugas, peran dan tanggung jawab masing-masing pihak yang terlibat.

Dimensi kompromi dalam mengatasi perbedaan cara kerja dalam collaborative governance dalam pencegahan kebakaran hutan dan lahan gambut dilakukan dengan rapat koordinasi terlebih dahulu untuk menyamakan persepsi. Rapat koordinasi dilakukan sekali dalam satu tahun apabila sudah ditetapkan BMKG telah masuknya musim kemarau sebagai upaya pemerintah, swasta dan masyarakat dalam bekerja sama untuk mencegah agar tidak terjadi kebakaran. Namun rapat koordinasi yang dilakukan kurang efektif apabila hanya dilakukan dalam satu kali dalam setahun mengingat kebakaran hutan dan lahan gambut yang terjadi merupakan permasalahan nasional dan terus menerus terjadi setiap tahun.

\section{Communication}

Pemerintah melakukan komunikasi bersama swasta dan masyarakat dengan mengadakan rapat koordinasi dan sosialisasi. Model komunikasi yang terjalin diantara pemerintah, swasta dan masyarakat dalam melakukan kolaborasi pencegahan kebakaran hutan dan lahan gambut, yaitu komunikasi dua arah sehingga tercipta kesamaan pengertian dan tidak menimbulkan berbagai macam perbedaan persepsi. Jadi tidak hanya pemerintah saja yang mengkomunikasikan, tetapi swasta dan masyarakat juga turut mengkomunikasikan sesuai dengan kepentingannya. Namun penulis menemukan fakta bahwa komunikasi yang terjalin antara pemerintah, swasta dan masyarakat kurang berjalan dengan baik.

Hal ini terbukti dari rapat koordinasi yang dilakukan hanya satu kali dalam satu tahun dan rapat koordinasi tersebut tidak efektif karena waktu yang sangat singkat untuk membahas masalah kebakaran hutan dan lahan gambut yang menjadi permasalahan nasional. Sosialisasi yang dilakukan juga kurang efektif karena sosialisasi dilakukan bejalan secara sendiri-sendiri oleh setiap aktor. Sosialisasi 
akan lebih maksimal apabila dibuat suatu program penyelenggaraan pencegahan kebakaran hutan dan lahan gambut yang melibatkan ketiga aktor secara langsung turun ke lapangan. Hal ini menunjukkan bahwa komunikasi yang berjalan kurang efektif karena komunikasi tidak berjalan secara rutin dan tidak terstruktur.

\section{Democracy and equality}

Kolaborasi pemerintah, swasta dan masyarakat dibangun dalam prinsip demokrasi yang menekankan nilai-nilai persamaan kedudukan, bebas bekerjasama, kebebasan mengemukakan ide dan pikiran tentang apa saja yang dianggap penting dalam menunjang keberhasilan dalam pencegahan kebakaran hutan dan lahan gambut. Pemerintah memposisikan swasta dan masyarakat dianggap mampu bekerja secara bersama-sama dalam mencapai tujuan bersama. Sehingga pengambilan keputusan yang ditandatangani dalam notulen merupakan hasil kesepakatan bersama.

Pelibatan swasta dan masyarakat untuk mencapai tujuan publik merupakan ciri dari pemerintahan yang responsif. Nilai demokrasi dalam pencegahan kebakaran hutan dan lahan gambut dicirikan dengan berpartisipasinya swasta dan masyarakat dalam pengambilan keputusan yang mana kondisi ini membuktikan bahwa pemerintah dalam bertindak menempatkan semua pihak dalam posisi yang sama sehingga swasta dan masyarakat memiliki akses dan perlakuan yang sama dalam berkolaborasi. Hal ini berarti nilai demokrasi yang sudah diterapkan tersebut juga merupakan penghargaan, kesejajaran dan adanya nilai persamaan dalam kolaborasi pencegahan kebakaran hutan dan lahan gambut.

\section{Power and trust}

Dalam pencegahan kebakaran hutan dan lahan gambut, pemerintah memiliki peran birokrasi untuk menggerakkan swasta dan masyarakat agar ikut berpartisipasi dalam pencegahan kebakaran hutan dan lahan gambut. Besarnya kekuasan pemerintah tidak kemudian menjadi dominan, tetapi kekuasaan yang dimiliki pemerintah bermaksud untuk memba- ngun interaksi dengan swasta dan masyarakat untuk dapat saling bekerja sama dalam menyelesaikan masalah publik. Pemerintah tidak hanya mengeluarkan perintah-perintah saja namun ikut turut andil turun kelapangan mempersiapkan apa saja yang diperlukan untuk pencegahan kebakaran hutan dan lahan seperti melakukan rapat koordinasi, sosialisasi, pelatihan, penyebaran spanduk, penyebaran brosur dan sebagainya.

Birokrasi yang bertindak etis, adil dan sesuai dengan aturannya dan memiliki niat baik serta selalu peduli dengan kondisi sosial mereka, maka hal ini kemudian berimplikasi pada tingkat kepercayaan (trust) swasta dan masyarakat terhadap pemerintah dalam upaya berkolaborasi dalam pencegahan kebakaran hutan dan lahan gambut. Penerapan kepercayaan masyarakat dan swasta kepada pemerintah mendorong keinginan swasta dan masyarakat untuk bisa bekerjasama dengan baik. Dengan demikian, pencegahan kebakaran hutan dan lahan gambut mengedepankan sikap saling percaya dan saling membantu satu sama lain agar terwujudnya tujuan bersama. Hal ini berimplikasi pada proses kerja lebih mudah karena saling percaya dan saling mengerti apa tugas dan perannya masing-masing.

\section{Determination, commitment and stamina}

Hubungan para aktor harus dibangun dan didasari dengan commitment (komitmen) yang kuat, sehingga dapat mempermudah terwujudnya penyelenggaraan pemerintahan yang baik. Pemerintah, swasta dan masyarakat memiliki keinginan yang kuat, determination (kebulatan tekad) serta memiliki commitment (komitmen) untuk terus bersama-sama saling bekerjasama dalam mencapai tujuan awal dilakukannya kolaborasi dalam pencegahan kebakaran hutan dan lahan gambut. Sebagai wujud kebulatan tekad dan komitmen pemerintah, pemerintah memberikan sarana prasarana dan sosialiasi serta memberikan pelatihan kepada MPA untuk lebih mengolah kemampuan yang dimiliki masyarakat.

Wujud kebulatan tekad dan komitmen swasta, PT. BBHA memberikan fasilitas, 
pembinaan dan insentif kepada MPA setiap bulannya. Sedangkan wujud tekad dan komitmen masyarakat yaitu, masyarakat akan terus meningkatkan rasa keperdulian kepada lingkungan dan akan terus berpartisipasi dalam pencegahan kebakaran hutan dan lahan ini.

Stamina dibangun atas dasar rasa saling percaya antara pemerintah, swasta dan masyarakat. Apa yang harus dilakukan oleh masingmasing pihak yang terlibat dalam kolaborasi ditentukan oleh kapasitas masing-masing dalam mewujudkan tujuan bersama. Kegiatan yang berbeda-beda oleh masing-masing aktor harus didukung oleh setiap pihak dalam pencapaian tujuan tersebut. Sehingga terjadi hubungan yang harmonis antar aktor serta berdampak pada meningkatnya daya tahan dan dukungan swasta dan masyarakat kepada pemerintah untuk mewujudkan tujuan bersama yang ingin dicapai yaitu mencegah agar kebakaran hutan dan lahan gambut tidak terjadi lagi.

\section{SIMPULAN}

Collaborative governance dalam pencegahan kebakaran hutan dan lahan gambut di Kabupaten Bengkalis belum berjalan secara maksimal. Ada beberapa indikator yang belum berjalan dengan baik. Dilihat dari indikator managing aims, setiap aktor memiliki tujuan yang sama namun tujuan tersebut belum tercapai secara maksimal. Dilihat dari indikator compromise, rapat koordinasi sebagai dimensi kompromi belum berjalan efektif karena hanya dilakukan satu kali dalam setahun. Dilihat dari indikator communication, komunikasi yang berjalan kurang efektif karena komunikasi tidak berjalan secara rutin dan tidak teratur. Dilihat dari indikator democracy and equality, proses pengambilan keputusan pemerintah turut melibatkan swasta dan masyarakat, kondisi ini membuktikan bahwa pemerintah dalam bertindak menempatkan semua pihak dalam posisi yang sama. Dilihat dari indikator power and trust, pemerintah memanfaatkan kekuatan yang dimiliki untuk mempengaruhi swasta dan masyarakat agar ikut bekerjasama, sedangkan swasta dan masyarakat memiliki kepercayaan yang penuh kepada pemerintah. Dilihat dari indikator determination, commitment, and stamina, ketiga stakeholder yang terlibat memiliki kebulatan tekad dan komitmen serta memiliki daya tahan untuk terus bekerjasama.

\section{DAFTAR RUJUKAN}

Adianto, Rendi Prayuda. 2018. Collaborative Governance dalam Kebijakan Lingkungan. Jurnal Good Governance, Vol. 14 No.2 Budiningsih, Kushartati. 2016. Implementasi Kebijakan Pengendalian Kebakaran Hutan dan Lahan di Provinsi Sumatera Selatan. Jurnal Analisis Kebijakan Kehutanan, Vol. 14 No. 2

Donahue, John D. and Richard J. Zeckhauser. 2011. Collaborative Governance: Private Roles for Public Goals in Turbulent Times. Princeton: Princeton University Press

Dwiyanto, Agus. 2012. Manajemen Pelayanan Publik: Peduli, Inklusif, dan Kolaboratif. Yogyakarta: Gadjah Mada University Press

Irawan, Denny. 2017. Proses Pemerintahan Kolaboratif dalam Pengendalian Pencemaran Udara di Kota Surabaya. Jurnal Kebijakan dan Manajemen Publik, Vol. 5

Kartika, Anna Sylviana, dkk. 2014. Buku Panduan Pencegahan Kebakaran Hutan dan Lahan Berbasis Desa di Areal Gambut. Jakarta: Kementrian Kehutanan

Meiwanda, Geovani, 2016. Kapabilitas PemerintahDaerah Provinsi Riau:Hambatan dan Tantangan Pengendalian Kebakaran Hutan dan Lahan. Jurnal Ilmu Sosial dan Ilmu Politik. Vol. 19 No. 3

Sabaruddin,Abdul. 2015. Manajemen Kolaborasi dalam Pelayanan Publik: Teori, Konsep dan Aplikasi. Yogyakarta: Graha Ilmu

Sandhyavitri, Ari, dkk. Pemadaman Kebakaran Lahan Gambut Secara In-situ. Pekanbaru: UR Press

Subarsono, Agustinus. 2016. Kebijakan Publik dan Pemerintahan Kolaboratif Isu-Isu Kontemporer. Yogyakarta: Gava Media 